\title{
Young Professionals Committee: Providing a Service to Young TMS Members and the Society
}

\section{Douglas Spearot}

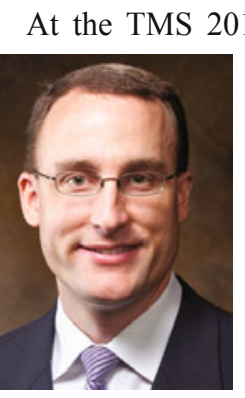

Douglas Spearot
013 Annual Meeting in San Antonio, Texas, the Young Leaders Committee formally voted to change its name to the Young Professionals Committee. While this change may seem subtle, it better represents the constituents of the committee and the impact that the committee will have on the society in the future. The role of the Young Professionals Committee is (1) to provide services to young TMS members including students and early career professionals, (2) to recognize outstanding young TMS members at early points in their careers, and (3) to make young TMS members aware of other volunteer activities in the society. Let me emphasize that the Young Professionals Committee is open to any active TMS member age 40 and younger, regardless of whether that member has received a Young Leader award from TMS.

The Young Professionals Committee is engaged in a wide variety of activities that provide critical professional services to young TMS members. For example, one of the newest programming initiatives of the Young Professionals Committee is the Meet the Candidate Poster Session. This poster session is specifically designed to showcase the research of graduate students in their final year of studies to potential employers in academia, industry, and national laboratories. At the most recent meeting in San Antonio, 21 students presented posters with representatives from academia, indus- try and national laboratories present. The Meet the Candidate Poster Session provides a unique service to both graduate students employers, and our goal is to get more representatives from these groups engaged in this opportunity at future TMS Annual Meetings.

Further, over the last decade, the Young Professionals Committee has organized the Student Career Forum where a panel of TMS members from academia, industry, and national laboratories is assembled to answer questions from undergraduate and graduate students on topics that range from applying to graduate school to starting a company based on their research. I participated on this panel for the first time this year and was impressed with the experiences of the panelists and the openness of students to ask questions during (and after) the session.

TMS bestows several awards dedicated to young TMS members that recognize outstanding achievement or future leadership promise within the materials science field. The Young Leader Professional Development Award is one of several awards designed to motivate involvement of young TMS members in both the Young Professionals Committee and technical committees in their area of expertise. Historically, 10 winners were selected for this award annually Using 2012 data, $46 \%$ of Young Leader Professional Development Award winners from 1996-2011 currently hold leadership positions at the committee, division, or Board-of-Directors level and nearly $60 \%$ of registered Young Professionals Committee members are registered members of a technical committee in TMS. Recognizing this success, TMS doubled the number of award winners for the Annual Meeting in San Antonio and will triple the number of Young Leader Professional Development Awards to 30 for the 2014 Annual Meeting.

TMS also recognizes young members via the TMS Young Leader International Scholar Awards, in collaboration with the Japan Institute of Metals (JIM) to attend the spring JIM meeting and with the Federation of European Materials Societies to attend EUROMAT. Finally, TMS presents the Early Career Faculty Fellow Award which recognizes one young faculty member annually who has made a tremendous impact both on the society and in their individual field of research.

Ultimately, the Young Professionals Committee provides a path with a low energy barrier for young TMS members to become involved as volunteers in the society. The Young Professionals Committee meeting in San Antonio was the largest of those that I have attended due to the expansion of the Young Leader Professional Development Award. With continued growth in the number of active members, the Young Professionals Committee will be able to further enhance activities which provide services to young TMS members and the society. I invite all eligible TMS members to get involved in the Young Professionals Committee and to bring new ideas to the table regarding how we as a society can help support the future generation of materials scientists and engineers.

Douglas Spearot is an associate professor of Mechanical Engineering, University of Arkansas; and chair of the TMS Young Professionals Committee. 